eCommons@AKU

February 2018

\title{
Bladder distension as a cause of abdominal compartment syndrome
}

\author{
Muhammad Yasir \\ Security Forces Hospital, Riyadh, Saudi Arab \\ Muhammad Qamarul Hoda \\ Aga Khan University, qamar.hoda@aku.edu \\ Tauseef Ahmed \\ Manchester Royal InfirmaryHospital, Oxford Road, Manchester
}

Follow this and additional works at: https://ecommons.aku.edu/pakistan_fhs_mc_anaesth

Part of the Anesthesiology Commons, and the Urology Commons

\section{Recommended Citation}

Yasir, M., Hoda, M. Q. Ahmed, T. (2018). Bladder distension as a cause of abdominal compartment syndrome. Journal of the College of Physicians and Surgeons Pakistan, 28(2), 155-156.

Available at: https://ecommons.aku.edu/pakistan_fhs_mc_anaesth/130 


\title{
Bladder Distension as a Cause of Abdominal Compartment Syndrome
}

\author{
Muhammad Yasir1, Muhammad Qamarul Hoda² and Tauseef Ahmed 3
}

\begin{abstract}
Abdominal compartment syndrome (ACS) is increasingly identified in critically ill patient and its harmful effects are well documented. The disparity among the pressure, volume in abdominal cavity and its contents, results in ACS. The actual incidence of ACS is not known. However, it has been observed predominantly in patients with severe blunt and penetrating abdominal trauma, ruptured abdominal aortic aneurysms, retro- and intra-peritoneal hemorrhage, pneumoperitoneum, neoplasm, pancreatitis, ascites and multiple bone fracture. We present a case of 40-year female who underwent emergency cesarean section and developed abdominal compartment syndrome due to urinary bladder distension secondary to blockade of urinary catheter with blood clots. This is a very unusual cause of ACS.
\end{abstract}

Key Words: Abdominal compartment syndrome. Intra-abdominal pressure. Urinary catheter.

\section{INTRODUCTION}

Abdominal compartment syndrome (ACS) has been increasingly recognized in critically ill patient. If unrecognized and untreated, it is associated with high mortality. ${ }^{1}$ ACS may be caused by conditions that increase the pressure in the abdomen due to increase in abdominal or retro-peritoneal volume/contents. ${ }^{2}$ This increased intra-abdominal pressure (IAP) adversely affects cardiovascular and respiratory systems with resultant decrease in venous return, cardiac output, and increased airway pressures with hypoxia and hypercapnia along with decreased chest compliance. As a result of increased intra-abdominal pressure, perfusion to major abdominal organs is compromised and renal circulation also reduce with resultant decrease in urine output.3,4

Classical examples of intra-abdominal hypertension (IAH) and ACS were described after damage control surgery in trauma and in those patients undergoing massive fluid resuscitation for any reasons. Incidence of ACS after abdominal surgery varies from low after elective surgery to considerably high after emergency procedures. ${ }^{5}$ The clinical suspicion of raised intraabdominal pressure in patients with associated risk factors is the key for the early diagnosis and subsequent treatment of ACS by abdominal decompression, in order to avoid multiple organ failure. 6

1 Department of Anaesthesiology, Security Forces Hospital, Riyadh, Saudi Arab.

2 Department of Anaesthesiology, The Aga Khan University and Hospital, Karachi.

3 Department of Anaesthetic, Manchester Royal Infirmary Hospital, Oxford Road, Manchester.

Correspondence: Dr. Muhammd Yasir, Consultant, Department of Anaesthesiology, Security Forces Hospital, P.O. Box 3643, Riyadh 11481, Saudi Arab.

E-mail: yasirdr@hotmail.com

Received: November 25, 2015; Accepted: November 20, 2017.
We report a case of abdominal compartment syndrome caused by postoperative urinary bladder distension secondary to blockade of urinary catheter with blood clots in a 40-year female patient who underwent emergency cesarean section. As per our knowledge, this is the only case report of abdominal compartment syndrome due to bladder obstruction.

\section{CASE REPORT}

A 40-year female with no known comorbid condition, was planned for elective cesarean section due to type IV placenta previa, poly hydramnios and poor obstetric history.

Two days earlier to her planned procedure, she presented in labour room with a history of four hours of labour pain for which emergency lower cesarean section was undertaken. Her preoperative assessment was normal and she underwent surgery under general anaesthesia.

Intraoperative course was complicated by massive blood loss (6-7 liters) for which she was given 13 units of packed red blood cell (PRBC), 11 units of fresh frozen plasma (FFP), 8 units of platelets, 8 units of cryoprecipitate, 12 litres colloid, and 3 litres of crystalloid. Hemostasis was difficult to achieved so a cesarean hysterectomy was performed as a rescue. A diagnosis of disseminated intravascular coagulopathy was made clinically; abdominal closure was difficult, therefore, the wound was left open and covered with soaked abdominal packs. She required ionotropic support with dopamine at $20 \mathrm{mcg} / \mathrm{kg} / \mathrm{min}$ and epinephrine at $0.05 \mathrm{mcg} / \mathrm{kg} / \mathrm{min}$. She was electively ventilated postoperatively. Patient was kept sedated. On inotropic support with dopamine and epinephrine, she was maintaining her systolic arterial pressure between $90-110 \mathrm{mmHg}$, with a CVP of 5-7 $\mathrm{cm} \mathrm{H}_{2} \mathrm{O}$. Her abdominal girth was monitored hourly. She received 6 units of red cells concentrate, 10 units of cryoprecipatate, 4 units of fresh frozen plasma and six units of platelets within first 
18 hours postoperatively. She became oliguric followed by an increase in the abdominal girth from a baseline of $93 \mathrm{~cm}$ to $101 \mathrm{~cm}$. Subsequent to that, her CVP also dropped to $2 \mathrm{~cm} \mathrm{H}_{2} \mathrm{O}$ and she became severely hypotensive with a blood pressure of $56 / 32 \mathrm{mmHg}$ and heart rate went up to $135 /$ minute. A surgical review was sought immediately and provisional diagnosis of intraabdominal bleeding was made. For the management of this life-threatening peri-arrest condition, she was immediately transferred to operating room. Reexploratory laparotomy was negative for any active bleeding with minimal amount of intraperitoneal blood stained fluid. The most striking finding was an enormously distended urinary bladder, extending from pubic symphysis up to umbilicus, which was confirmed by needle aspiration. On examination, it was found that urinary catheter was blocked with blood clots which was replaced and drained about $1400 \mathrm{ml}$ urine.

Following the decompression of urinary bladder, immediate improvement was noticed in her blood pressure with decreasing requirement of dopamine. Her blood pressure increased to $140 / 70 \mathrm{mmHg}$ and heart rate came down to 110 per minute, and the urine output increased to $200 \mathrm{ml} /$ hour. The peak airway pressure also dropped from $30 \mathrm{~cm} \mathrm{H}_{2} \mathrm{O}$ to $20 \mathrm{~cm} \mathrm{H}_{2} \mathrm{O}$. Her CVP increased to $12 \mathrm{~cm} \mathrm{H} \mathrm{H}_{2} \mathrm{O}$. It was decided to put abdominal pack and not to close the abdominal wound at this stage. Patient was transferred to post anaesthesia care unit for elective ventilation. On the very next day, her inotropes were successfully tapered off. Two days later, patient was again taken to operating room for removal of abdominal packs and wound closure. She remained stable and was extubated on the next day and shifted to high dependency unit and later discharged home after 10 days in good condition.

\section{DISCUSSION}

ACS is a disorder associated with significant morbidity and mortality, refers to organ dysfunction resulting from increased intra-abdominal pressure (IAP). ${ }^{7}$ ACS, defined by world society of abdominal compartment syndrome as intra-abdominal pressure of at least $20 \mathrm{~mm}$ $\mathrm{Hg}$ with dysfunction of at least one thoraco-abdominal organ. ${ }^{8}$ This increase in intra-abdominal pressure leads to organ dysfunction involving primarily heart and lungs. ${ }^{9}$ The reason for cardiac symptoms are multifactorial with decreased preload due to compression of both the portal vein and inferior vena cava, and an increased afterload due to increased systemic vascular resistance, leading to a decreased stroke volume and thus decreased cardiac output and cardiac arrest with pulseless electrical activity (PEA). The main reasons for respiratory compromise are the combination of cephaled displacement of the diaphragm, with resultant decrease in total and residual lung volume and lung compliance. ${ }^{7}$
The standard recommended method for diagnosis and management of IAH and ACS is based on accurate and repeated measurements of its surrogate pressure; intravesical urinary bladder pressure. ${ }^{3}$ But in peri-arrest situations, when there is no time to measure IAP, clinical signs of organ dysfunctions, and hypoperfusion with low cardiac output, hypoxia, tense distended abdomen, progressive oliguria or anuria are sufficient to justify emergency decompression. ${ }^{10}$

In this case, the diagnosis was also made by clinical parameters only because of deteriorating and near crash situation which developed suddenly. The intravesical pressure was not measured as she had to be rushed to operating room while cardiopulmonary resuscitation was actively going on.

This patient had signs and symptoms that could suggest hypovolemic/septic shock (tachycardia, severe hypotension, tachypnea, fever and decreased urine output). However, following emergency surgical decompression, the patient had a prompt normalization of her vital signs and urine output. In view of the above, a distended urinary bladder, due to catheter block, was the most likely diagnosis of her deterioration. There was no case report of ACS secondary to urinary catheter obstruction.

\section{REFERENCES}

1. Parsak CK, Seydaoglu G, Sakman G, Acarturk OT, Karakoc E, Hanta I, et al. Abdominal compartment syndrome: current problems and new strategies. World J Surg 2008; 32:13-9.

2. Hunter JD, Damani Z. Intra-abdominal hypertension and the abdominal compartment syndrome. Anaesthesia 2004; 59:899-907.

3. Kavaguti SK, Mackevicius BR, Andrade MF, Tucci S, Carlotti AP. Abdominal compartment syndrome caused by massive pyonephrosis in an infant with primary obstructive megaureter. Case Rep Med 2011; 10:1-4

4. Bailey J, Shapiro MJ. Abdominal compartment syndrome. Crit Care 2000; 4:23-29.

5. Berry N, Fletcher S. Abdominal compartment syndrome. Continuing Education in Anaesthesia, Crit Care Pain 2012; 12: 110-7.

6. Mahajna A, Mitkal S, Krausz MM. Postoperative gastric dilatation causing abdominal compartment syndrome. World $J$ Emerg Surg 2008; 3:7.

7. Souadka A, Mohsine R, Ifrine L, Belkouchi A, Malki HOE. Acute abdominal compartment syndrome complicating a colonoscopic perforation: a case report. J Med Case Rep 2012; 6:51.

8. Patel A, Chandana G. Lall CG, Jennings SG, Sandrasegaran K. Abdominal compartment syndrome. Am J Roentgenol 2007; 189:1037-43.

9. Papavramidis TS, Marinis AD, Pliakos I, Kesisoglou I, Papavramidou N. Abdominal compartment syndrome - Intraabdominal hypertension: defining, diagnosing, and managing. J Emerg Trauma Shock 2011; 4: 279-91.

10. Carlotti CP, Carvalho WB. Abdominal compartment syndrome: a review. Pediatr Crit Care Med 2009; 10:115-20.

.......... 